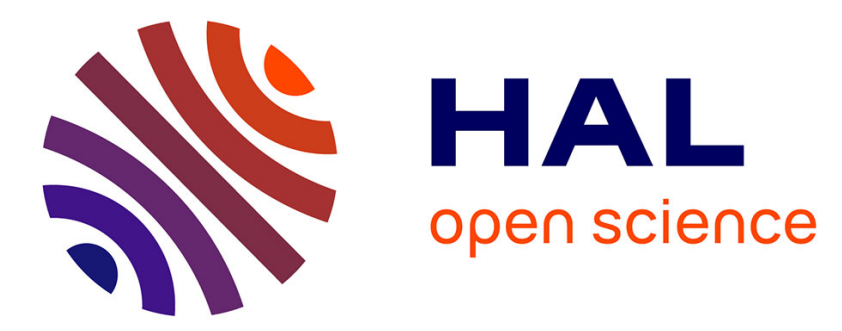

\title{
Detection and management of dyspnea In mechanically ventilated patients
}

\author{
Maxens Decavele, Alexandre Demoule, Thomas Similowski
}

\section{To cite this version:}

Maxens Decavele, Alexandre Demoule, Thomas Similowski. Detection and management of dyspnea In mechanically ventilated patients. Current Opinion in Critical Care, 2019, 25 (1), pp.86-94. 10.1097/MCC.0000000000000574 . hal-02271758

\section{HAL Id: hal-02271758 \\ https://hal.sorbonne-universite.fr/hal-02271758}

Submitted on 27 Aug 2019

HAL is a multi-disciplinary open access archive for the deposit and dissemination of scientific research documents, whether they are published or not. The documents may come from teaching and research institutions in France or abroad, or from public or private research centers.
L'archive ouverte pluridisciplinaire HAL, est destinée au dépôt et à la diffusion de documents scientifiques de niveau recherche, publiés ou non, émanant des établissements d'enseignement et de recherche français ou étrangers, des laboratoires publics ou privés. 


\title{
Detection and management of dyspnea
}

\section{In mechanically ventilated patients}

\author{
Maxens Decavèle M.D. ${ }^{1,2}$, Thomas Similowski M.D., Ph.D. ${ }^{1,2}$, \\ Alexandre Demoule M.D., Ph.D. ${ }^{1,2}$
}

(1) Sorbonne Université, INSERM, UMRS1158 Neurophysiologie Respiratoire Expérimentale et Clinique, F-75005 Paris, France

(2) AP-HP, Groupe Hospitalier Pitié-Salpêtrière Charles Foix, Service de Pneumologie Medecine Intensive Réanimation du Département R3S, F-75013 Paris, France

\section{Authors email addresses:}

Maxens Decavèle: maxencesar@hotmail.fr

Thomas Similowski: thomas.similowski@aphp.fr

Alexandre Demoule: alexandre.demoule@aphp.fr

\section{Corresponding author}

Prof. Alexandre Demoule

Service de Pneumologie Médecine Intensive Réanimation

Groupe Hospitalier Pitié-Salpêtrière

47-83 Boulevard de l'Hôpital

75013 Paris, France

Phone: 33142167761 ; $\quad$ Fax: 33142167843

e-mail: $\underline{\text { alexandre.demoule@aphp.fr }}$ 


\section{Acknowledgements section}

\section{Acknowledgements}

none

\section{Financial support and sponsorship}

none

\section{Conflicts of interest}

Maxens Decavèle has non conflicts of interest to declare.

Thomas Similowski has received grant research from Coviden, Philips, Pierre Fabre Médicaments, Air Liquide Medical Systems; he has also received personal fees from Takeda, Teva Pharma, Lungpacer Inc, Almirall France, Pierre Fabre Médicaments, Novartis, Mundipharma, Invacare, Astra Zeneca, Boehringer Ingelheim and GlaxoSmithKline.

Alexandre Demoule has signed research contracts with Covidien, Maquet, Philips and Ait Liquide Santé; he has also received personal fees from Covidien, Maquet and MSD. 


\begin{abstract}
Purpose of the review. In intensive care unit (ICU) patients, dyspnea is one of the most prominent and distressing symptom. We sought to summarize current data on the prevalence and prognostic influence of dyspnea in the ICU setting and to provide concise and useful information for dyspnea detection and management.

Recent findings. As opposed to pain, dyspnea has been a neglected symptom with regard to detection and management. Many factors contribute to the pathogenesis of dyspnea. Among them, ventilator settings seem to play a major role. Dyspnea affects half of mechanically ventilated patient and causes immediate intense suffering (median dyspnea visual analog scale of 5 [4-7]). In addition, it is associated with delayed extubation and with an increased risk of intubation and mortality in those receiving noninvasive ventilation. However, one third of critically ill patients are noncommunicative, and therefore at high risk of misdiagnosis. Heteroevaluation scales based on physical and behavioral signs of respiratory discomfort are reliable and promising alternatives to self-report.

Summary. Dyspnea is frequent and severe in critically ill patients. Implementation of observational scale will help physicians to access to non-communicative patient's respiratory suffering and tailor its treatment. Further studies on the prognostic impact and management strategies are needed.
\end{abstract}

Keywords: Dyspnea, evaluation, non-communicative patient, intensive care unit, heteroevaluation scale 
Over the past decade, growing attention has been given to the detection and treatment of pain in intensive care unit (ICU) patients. Interestingly, during the same period, very little attention has been given to dyspnea. Indeed, data regarding dyspnea in ICU patients are scarce and there are basically no recommendations regarding the assessment and the management of dyspnea in ICU patients. Beyond being a major source of discomfort, dyspnea shares many physiological and clinical features with pain. This should make it a major preoccupation for ICU physicians and nurses whose mission is to relieve symptoms in addition to treating disease processes. However, it might be a challenging issue in mechanically ventilated patients whose ability to communicate is limited.

The objective of the present review is to provide information regarding the prevalence and the risk factors of dyspnea in mechanically ventilated ICU patients. It is also to suggest some approaches to detect, quantify and manage dyspnea in these patients.

\section{Prevalence of dyspnea}

Dyspnea is the subjective experience of breathing discomfort. As a result, dyspnea should be self-reported by the patient [1]. Although respiratory distress is generally associated with dyspnea, a patient may experience dyspnea without exhibiting objective respiratory signs, rendering its detection sometimes complex [2].

In unselected non-intubated critically ill patients, dyspnea assessed by visual analogic scale (D-VAS, ranging from 0 [no dyspnea] to 10 [worst possible dyspnea]) appears to be frequent (circa 50\%) and severe (median [IQR] of 4.5 [3.2 - 6.0]) [3-5**]. Whereas mechanical ventilation is supposed to alleviate dyspnea caused by acute respiratory failure (ARF), the prevalence of dyspnea among intubated patients remains similar (circa 50\%) [6**, $7 *, 8^{*}$, with the same "moderate to severe" intensity (median D-VAS, 5 [4 - 7]). In patients 
receiving non-invasive ventilation (NIV) as first line treatment for ARF, 55\% present a moderate-to-severe dyspnea before NIV initiation and $39 \%$ after the first NIV session [9].

\section{Clinical relevance of dyspnea}

There is growing evidence suggesting that dyspnea has a deleterious impact on mechanically ventilated patients. The consequences of dyspnea may occur either immediately during the ICU stay or be delayed.

\subsection{Immediate suffering}

Patients with lung cancer presenting dyspnea have reported terrifying feelings such as: “it's a feeling... you're going to die because you're not getting enough air"; "if I felt I had to live my life feeling like that I would jump out the window" [10]. With visual analogic scale (VAS) ratings of $\geq 4$ in most of cases, dyspnea appeared to qualify as "moderate to intense" $\left[6^{* *}\right]$. Similar pain ratings are an indication for analgesia.

In addition, in mechanically ventilated patients, dyspnea is independently and strongly associated with anxiety $\left[6^{* *}\right]$. This is not surprising since the interplay between anxiety and dyspnea is complex and causative relationships can exist in both directions. Anxiety-relieving interventions could thus have a positive effect on respiratory rhythm and anxiety decreases in patients who reported improvements of dyspnea after adjustments of the ventilator settings $\left[6^{* *}\right]$.

\section{$2.2 \quad$ Impact on outcomes}

In addition to the burden that it represents for the patients that it afflicts, dyspnea is also a marker of a worse prognosis [11]. Indeed, in patients with respiratory or cardiac disorders, dyspnea is strongly associated with reduced life expectancy $[12,13]$. 
In intubated patients, persistent dyspnea despite an optimization of ventilator settings is associated with delayed extubation [6**]. In addition, the median intensity of dyspnea at the end of a spontaneous breathing trial (SBT) is higher in patients who fail than in those who succeed the SBT [14]. However, whether the presence of dyspnea or its intensity is associated with a higher mortality in intubated patients is not demonstrated [6**]. Data from a recently completed multicenter observational study (NCT02336464) may address this question. In patients receiving NIV, the persistence of a moderate-to-severe dyspnea after the first NIV session is independently associated with NIV failure and mortality [9].

\subsection{Delayed impact of dyspnea}

Patients' recollections of their ICU experience point to dyspnea during mechanical ventilation as a major ICU stressor $[15,16]$. Dark "respiratory recollections" may persist for several weeks. When questioned 2-48 months after discharge, $47 \%$ of patients who had been mechanically ventilated during ICU stay reported having felt anxiety and/or fear during mechanical ventilation [17].

Post-Traumatic Stress Disorder (PTSD) is now recognized as a common sequel of the ICU experience [18]. Recalled dyspnea is associated with post-traumatic stress (PTSD) in ICU survivors [18] and PTSD symptom scores in the post-ICU population are significantly correlated with duration of mechanical ventilation [19].

\section{Detection of dyspnea}

As is the case with pain, assessment of dyspnea depends on self-report", which requires the patient to be communicative. In case the patient is not, surrogates will be used. Figure 1 proposes an algorithm for dyspnea assessment in the critically or terminally ill patients. 


\subsection{Communicative patients: the Self-report approach}

\subsubsection{Unidimensional tools: measure dyspnea intensity}

Self-evaluation of dyspnea requires 1) to ensure the patient is able to report dyspnea, 2) to assess the presence or absence of dyspnea and 3) if dyspnea is present, to quantify its intensity.

In order to self-report dyspnea, the patient must be conscious and able to interpret sensory stimuli [20]. Clinical practice shows that conscious mechanically ventilated patients are generally able to answer simple questions about their respiratory sensations.

There is no clear criterion to attest that a patient is communicative. In a pragmatic approach, a reasonable awareness defined by Richmond Agitation and Sedation Scale score [21] between -2 and +2 associated with the absence of delirium according to the Confusion Assessment Method for the ICU (CAM-ICU) [22] are acceptable pre-requisite.

The following step is to detect the presence of dyspnea by dichotomic simple questions such as "do you breathe well," "is your breathing comfortable," "are you bothered by your breathing," "is your breathing difficult" and ensure that answers are concordant between at least two questions [1].

The last step is to measure the intensity of the dyspnea. Although more than 40 tools exist to assess dyspnea [23] none of them is ideal for critically ill patients. If the patient can point to a line, we recommend the use of the D-VAS, which is the gold standard in the general population and ensures a more precise continuous measure of dyspnea intensity [1]. An alternative is to use the $0-10$ Numeric Rating Scale (NRS), which consists in determining either verbally (between 0 and 10) or visually (on vertical or horizontal scale ranging from 0 to 10) which value corresponds to the patient's dyspnea intensity [24]. In patients who cannot associate numeric values to their symptoms, the modified dyspnea Borg scale (D-Borg) [25] might be used. It consists of verbal descriptors linked to specific numbers, in which the 
spacing of the numbers and corresponding descriptors essentially provides a category scale with ratio properties. This scale ranges from 0 , representing no dyspnea, to 10 , representing maximal dyspnea.

Clinically significant dyspnea is usually defined as D-VAS or D-NRS $\geq 4$, and "somewhat severe dyspnea" on modified Borg scale [5**, $\left.6^{* *}, 7^{*}, 9^{* *}, 26\right]$. First, such value corresponds to the lower quartile of dyspnea ratings in ICU patients experiencing dyspnea $\left[5^{* *}, 6^{* *}\right]$. Second, a D-NRS $\geq 4$ corresponds to a "moderate intensity" when compared to verbal descriptors [27]. Third, by analogy with pain, a VAS or NRS $\geq 4$ is also the lower threshold for "moderate-to-severe pain" and constitute a clear indication for prompt analgesic prescription [28]. Fourth, D-NRS $\geq 4$ in mechanically ventilated patients is associated with a higher risk of SBT failure [14], NIV failure and hospital mortality [9]. Thus, we consider that a dyspnea intensity $\geq 4$ is a clinically relevant dyspnea that must encourage caregivers for therapeutic interventions aimed at reducing its intensity.

\subsection{Detection of dyspnea in non-communicative patients}

One third of critically ill patients are unable to self-report sensations or symptoms [3$5^{* *}$. Main reasons are ongoing sedation, delirium, language barrier or sensory deficiency such as deafness. The fact that patients cannot communicate does not mean that they do not feel dyspnea and it is clear that these patients are exposed to the same risk factors of dyspnea than communicative patients [29]. Like observed with pain, it cannot be excluded that sedation, may give an external appearance of respiratory comfort, but falsely reassuring [30, 31]. Therefore, noncommunicative patients should rather be considered as a vulnerable population at high risk for misdiagnosis of dyspnea. 
Unfortunately, it is demonstrated that caregivers markedly underestimate patient's dyspnea in the ICU. In two recent studies, physicians, respiratory therapists and nurses markedly underestimated the intensity of dyspnea reported by the patient $\left[7^{*}, 8^{*}\right]$.

\subsubsection{Hetero-evaluation scales}

To address this major issue, hetero-evaluation scales of dyspnea based on physical and observable signs of respiratory distress are promising alternatives. The Respiratory Distress Observation Scale (RDOS) has been first developed in terminally ill patients and validated in non-communicative patients allowing identification of near-to-death patients who may benefit from oxygen therapy aimed at alleviated respiratory distress [32].

A version of this scale adapted to ICU patients, the Intensive Care - RDOS (IC-RDOS) has been developed [5**]. This scale includes five observable items (Figure 2) and is reliable in non-communicative critically ill patients. An IC-RDOS of 2.4 predicts a D-VAS $\geq 4$ with $72 \%$ sensitivity and $72 \%$ specificity. In mechanically ventilated patients, the Mechanical Ventilation - RDOS (MV-RDOS) is slightly more reliable to detect dyspnea than the ICRDOS (figure 2) [33*].

\subsubsection{Biomarkers of dyspnea}

Two electrophysiological markers of dyspnea are currently validated in healthy subjects and in patients: 1) the electromyographic activity of the extra-diaphragmatic inspiratory muscles [34] and 2) the premotor inspiratory potentials detected on the electroencephalogram $[35,36]$. Such biomarkers of dyspnea could help to detect and quantify dyspnea regardless of the patient's cooperation. Further research and development is needed. 


\section{The causes of dyspnea: physiopathology and risk factors}

Extensive reviews on dyspnea physiology can be found elsewhere [1, 37, 38]. The neurophysiological basis of dyspnea involves both excitatory and inhibitory afferent inputs from sensory nerves as well as perception of motor commands, named the "corollary discharge". The corollary discharge is an efferent copy of the respiratory motor output sent to the sensitive cortex. The sense of respiratory motor output that results from this copy is distinct from sensations directly related to changes in muscle length or tension. As illustrated in the Figure 3, in eupneic breathing, the corollary discharge (perception of motor command / sense of effort) is proportional to the afferent inputs. Dyspnea occurs as soon as there is an imbalance between the corollary motor discharge and the sensory peripheral response of the respiratory system.

In mechanically ventilated patients, dyspnea may results from a perception of the effort of breathing when the physical work of breathing is increased by an augmentation of respiratory muscle loading (ie. increased resistance and decreased compliance), or when cortical motor drive is increased because of respiratory muscle weakness [39]. It can also result from the conscious perception of the need for more air that arises from stimulation of chemoreceptors (rise in $\mathrm{PaCO}_{2}$ or a fall in $\mathrm{PaO}_{2}$ ) [40].

Finally, one of the most recent and striking developments in the field of pathophysiology of dyspnea is the recognition of the importance of the affective component of dyspnea. Both unpleasantness and emotional response can be differentially altered with different dyspnea modality or drug treatment [41]. Physiologically, the emotional component of dyspnea results from the cognitive-affective treatment of sensation, and is the basis of the corresponding short-term and long-term behavioral responses [42], hence its probable importance in the genesis of post-traumatic stress disorders syndrome observed after certain stays in intensive care [43]. 
To date, there is only 12 small sized, heterogeneous $\left[6^{* *}, 7^{*}, 8^{*}, 14,44-51\right]$ prospective studies on dyspnea in intubated patients. This is very few as compared to pain assessment [28], but these have identified various risk factors for dyspnea.

From a more clinical standpoint, the main determinant of dyspnea is the respiratory and circulatory state of the patient [52]. Altered respiratory mechanics (elevated resistance and low compliance) and altered gas exchange (hypoxemia and hypercapnia) are a clear cause of dyspnea. Various non-specific factors are susceptible to increase the ventilatory drive and cause dyspnea, such as anemia fever or acidosis. In addition, activities related to care such as nurse activities, bed transfers, bathing [41] or positioning [53] may also cause dyspnea. This is obviously the case for procedures such tracheal suctioning, or fiberoptic bronchoscopy [4].

However, inappropriate ventilator settings remain a leading cause of dyspnea in ICU patients: optimizing ventilator settings could reduce its intensity in $35 \%$ of patients exhibiting dyspnea [6]. The ACV mode is independently associated with dyspnea, especially when the inspiratory flow is $<60 \mathrm{~L} / \mathrm{min}$. Conversely, proportional assisted ventilation [54] and neutrally adjusted ventilator assist [55] are associated with less dyspnea. Clearly recommended strategies of lowering sedation, and the use of low tidal volumes [56] even in the absence of severe lung disorders $[57,58]$ are likely to increase the risk of dyspnea onset.

Finally, anxiety in intubated patients is strongly and independently associated with dyspnea and may increase per-se the ventilatory drive and the risk of dyspnea [6].

\section{Management of dyspnea in intubated patients}

Once dyspnea has been diagnosed, it is essential to have a step-by-step procedure to identify the cause of dyspnea and treat it in so far as this is possible (Figure 4).

\subsection{First reduce non-respiratory stimuli of respiratory drive}


As previously stated, many metabolic stimuli such as fever or hyperthermia may increase the respiratory drive. We suggest that, when it is not possible, not advisable or not logical to increase achieved ventilation, factors such as acidosis, hypoxia, hyperthermia, and anemia should be corrected [59].

\subsection{Minimize respiratory impedance and alterations of gas exchange}

Increased resistance or decreased compliance may promote both excessive effort and air hunger. When increased airway resistance is due to COPD or asthma, bronchodilators might be efficient. In the case of a reduced compliance due to a large pleural effusion, thoracocenthesis might be performed. In other cases, such as reduced pulmonary compliance due to pneumonia or a cardiogenic pulmonary edema, there is no other option than waiting for the benefit of the treatment of the causative disease.

Although is makes sense to avoid severe hypoxemia, robust data are lacking concerning the symptomatic response of dyspnea to supplemental oxygen [60].

\subsection{Optimise ventilator settings}

In patients receiving assist-controlled ventilation, the first step should be to evaluate the possibility of switching to a partial mode of assistance such as pressure support ventilation. If the patient needs to stay in assist-controlled ventilation, then the inspiratory flow has to be optimized and increased to over 1 liter/sec. If the patient is ventilated in pressure support ventilation, then the pressure support level might be increased, but over distention should be avoided. Finally, in the case of an intrinsic PEEP, the level of external PEEP might be set in order to compensate intrinsic PEEP, which is not always easy without invasive measurements.

\subsection{Consider pharmacologic approach}


If all the previous interventions have failed to decrease dyspnea, pharmacological approach might be considered. Opioids are the mainstay of pharmacological management of dyspnea with a clearly demonstrated effectiveness [61]. The doses of opioids required treating acute and severe dyspnea is not as well established than the does needed to treat acute pain. "Low and slow" intravenous titration of an immediate-release opioid, repeated every 15 min, until the patient reports or displays relief seems reasonable [62]

On the basis of current data, the use of nebulized diuretics for the management of dyspnea in terminally ill patients is still controversial and cannot be recommended [63]. Cannabinoid may be of potential interest, but more studies are required [64]. Given the strong interplay between anxiety and dyspnea, treating anxiety may reduce dyspnea, although the dose of anxiolytic should not depress respiratory drive [65].

\subsection{Non pharmacologic intervention}

Because of they have basically no toxicity, non-pharmacologic interventions have raised the interest of physicians. Various non-pharmacologic interventions to treat dyspnea such as walking aids, distractive auditory stimuli, chest wall vibration, acupuncture/acupressure, relaxation, neuro-electrical muscle stimulation, fans has been recently reviewed and their benefit is not so clear [62].

A promising approach would be to modulate the emotional and affective component of dyspnea by a pleasant music or positive pictures [66]. The modulation of the sensorial component of dyspnea is another approach. In palliative care patients with refractory dyspnea, ventilator-associated air delivery is associated with a 30\% decrease in dyspnea intensity [67]. 


\section{Conclusion}

There is growing evidence suggesting that dyspnea is frequent and severe in mechanically ventilated ICU patients. In these patients, dyspnea is highly associated with anxiety and might be linked to a poorer outcome. Heteroevaluation scale will help caregivers to detect respiratory suffering in non-communicative patients and tailor its treatment. Finally, the ventilator settings seem to be a major determinant of dyspnea.

Future large-scale studies are now needed. These studies should aim to quantify the prevalence of dyspnea in a very large population of patients through multicenter studies. They should also study the occurrence and the intensity of dyspnea on a longitudinal basis. This could allow physicians to know if dyspnea could be a monitoring tool that might predict an ongoing complication in an ICU patient. Finally, the long-term impact of dyspnea in ICU patients needs to be evaluated.

\section{Key bullet points}

In intubated patients, dyspnea is frequent, severely distressing and associated with poorer outcomes

Dyspnea assessment remains challenging in intubated patients and one third miss its evaluation because of impaired self-report abilities.

Heteroevaluation scales are promising alternatives to self-report making breathing discomfort evaluation possible in noncommunicative patients.

Critically ill patients may benefit from rigorous detection and multimodal therapeutics interventions aimed at reduce dyspnea but further studies are needed. 


\section{References}

[1] Parshall MB, Schwartzstein RM, Adams L, et al. An official American Thoracic Society statement: update on the mechanisms, assessment, and management of dyspnea. Am J Respir Crit Care Med. 2012;185(4):435-452.

[2]* Schmidt M, Banzett RB, Raux M, Morelot-Panzini C, Dangers L, Similowski T, Demoule A. Unrecognized suffering in the ICU: addressing dyspnea in mechanically ventilated patients. Intensive Care Med. 2014;40:1-10

Comprehensive review of dyspnea in intubated patients.

[3] Nelson JE, Meier DE, Oei EJ, et al. Self-reported symptom experience of critically ill cancer patients receiving intensive care. Crit Care Med 2001;29:277-282.

[4] Puntillo KA, Arai S, Cohen NH, et al. Symptoms experienced by intensive care unit patients at high risk of dying . Crit Care Med. 2010;38:2155-2160.

[5]** Persichini R, Gay F, Schmidt M, et al. Diagnostic Accuracy of Respiratory Distress Observation Scales as Surrogates of Dyspnea Self-report in Intensive Care Unit Patients. Anesthesiology. 2015;123:830-837.

This work is the development and validation study of the Intensive Care - Respiratory Distress Respiratory Scale (IC-RDOS), the first heteroevaluation scale of dyspnea adapted and optimized for non-intubated intensive care unit patients.

[6]** Schmidt M, Demoule A, Polito A, Porchet R, Aboab J, Siami S, Morelot-Panzini C, Similowski T, Sharshar T. Dyspnea in mechanically ventilated critically ill patients. Crit Care Med. 2011; 39:2059-2065.

First large prospective study of dyspnea in intubated patients. One third of cases, dyspnea can be alleviated with simple ventilator settings optimization.

[7]* Haugdahl HS, Storli SL, Meland B, Dybwik K, Romild U, Klepstad P. Underestimation of Patient Breathlessness by Nurses and Physicians during a Spontaneous Breathing Trial. Am J Respir Crit Care Med. 2015; 192: 1440-1448.

Underestimation of the intubated patient's dyspnea by cargivers

[8]* Binks AP, Desjardin S, Riker R. ICU Clinicians Underestimate Breathing Discomfort in Ventilated Subjects. Respir Care. 2017 62: 150-155.

Confirmation of a marked underestimation of the intubated patient's dyspnea by cargivers

[9]** Dangers L, Montlahuc C, Kouatchet A, et al. Dyspnoea in patients receiving noninvasive ventilation for acute respiratory failure: prevalence, risk factors and prognostic impact: A prospective observational study. Eur Respir J. 2018;9:52(2).

This study shows that patients with a persistent borg-dyspnea score $\geq 4$ after a first NIV session have an increased risk of intubation and hospital mortality.

[10] O'Driscoll M, Corner J, Bailey C. The experience of breathlessness in lung cancer. Eur J Cancer Care (Engl). 1999 Mar;8(1):37-43. 
[11] Santos M, Kitzman DW, Matsushita K, et al. Prognostic Importance of Dyspnea for Cardiovascular Outcomes and Mortality in Persons without Prevalent Cardiopulmonary Disease: The Atherosclerosis Risk in Communities Study. PLoS One. 2016;11:e0165111.

[12] Abu Hussein N, Ter Riet G, Schoenenberger L, et al. The ADO index as a predictor of two-year mortality in general practice-based chronic obstructive pulmonary disease cohorts. Respiration. 2014;88:208-214.

[13] Bernheim AM, Kittipovanonth M, Scott CG, et al. Relation of dyspnea in patients unable to perform exercise stress testing to outcome and myocardial ischemia. Am J Cardiol. 2009;104:265-269.

[14] Chen YJ, Hwang SL, Li CR, et al. Vagal withdrawal and psychological distress during ventilator weaning and the related outcomes. J Psychosom Res. 2017;101:10-16.

[15] de Miranda S, Pochard F, Chaize M, et al. Postintensive care unit psychological burden in patients with chronic obstructive pulmonary disease and informal caregivers: A multicenter study. Crit Care Med. 2011;39:112-118.

[16] Rotondi AJ, Chelluri L, Sirio C, et al. Patients' recollections of stressful experiences while receiving prolonged mechanical ventilation in an intensive care unit. Crit Care Med. 2002;30:746-752.

[17] Bergbom-Engberg I, Haljamäe H. Assessment of patients' experience of discomforts during respirator therapy. Crit Care Med. 1989;17:1068-1072.

[18] Cuthbertson BH, Hull A, Strachan M, Scott J. Post-traumatic stress disorder after critical illness requiring general intensive care. Intensive Care Med. 2004;30:450-455

[19] Shaw RJ, Harvey JE, Bernard R, et al. Comparison of short-term psychological outcomes of respiratory failure treated by either invasive or non-invasive ventilation. Psychosomatics. 2009;50:586-591.

[20] Campbell ML. Dyspnea. AACN Adv Crit Care. 2011;22(3): 257-264.

[21] Sessler CN, Gosnell MS, et. al. The Richmond Agitation-Sedation Scale: validity and reliability in adult intensive care unit patients.Am J Respir Crit Care Med. 2002 Nov 15;166(10):1338-44.

[22] Ely EW, Margolin R, Francis J, et al. Evaluation of delirium in critically ill patients : Validation of the Confusion Assessment Method for the Intensive Care Unit (CAM-ICU). Crit Care Med 2001;29:1370-1379.

[23] Mularski RA, Campbell ML, Asch SM, et al. A review of quality of care evaluation for the palliation of dyspnea. Am J Respir Crit Care Med. 2010;181:534-538.

[24] Gift AG, Narsavage G. Validity of the numeric rating scale as a measure of dyspnea. Am J Crit Care 1998;7:200-204. 
[25] Powers J, Bennett SJ. Measurement of dyspnea in patients treated with mechanical ventilation. Am J Crit Care 1999;8:254-261.

[26] Stevens JP, Dechen T, Schwartzstein R, et al. Prevalence of Dyspnea Among Hospitalized Patients at the Time of Admission. J Pain Symptom Manage. 2018;56:15-22.e2.

[27] Wysham NG, Miriovsky BJ, Currow DC, et al. Practical Dyspnea Assessment: Relationship Between the 0-10 Numerical Rating Scale and the Four-Level Categorical Verbal Descriptor Scale of Dyspnea Intensity. J Pain Symptom Manage. 2015;50:480-487.

[28] Devlin JW, Skrobik Y, Gélinas C, et al. Clinical Practice Guidelines for the Prevention and Management of Pain, Agitation/Sedation, Delirium, Immobility, and Sleep Disruption in Adult Patients in the ICU. Crit Care Med. 2018;46:e825-e873

[29] Demoule A, Persichini R, Decavèle M, Morelot-Panzini C, Gay F, Similowski T. Observation scales to suspect dyspnea in non-communicative intensive care unit patients. Intensive Care Med. 2018 Jan;44(1):118-120

[30] Hofbauer RK, Fiset P, Plourde G, Backman SB, Bushnell MC. Dose-dependent effects of propofol on the central processing of thermal pain. Anesthesiology. 2004; 100:386-394.

[31] Frolich MA, Zhang K, Ness TJ. Effect of sedation on pain perception. Anesthesiology. 2013; 118:611-621.

[32] Campbell ML. Respiratory distress: a model of responses and behaviors to an asphyxial threat for patients who are unable to self-report. Heart Lung. 2008 ; 37:54-60.

[33]** Decavèle M, Gay F, Persichini R, Mayaux J, Morélot-Panzini C, Similowski T, Demoule A. The Mechanical Ventilation-Respiratory Distress Observation Scale as a surrogate of self-reported dyspnoea in intubated patients. Eur Respir J. 2018 Oct 10;52(4).

Adaptation of the IC-RDOS for the intubated patients: MV-RDOS. First heteroevaluation scale dedicated to noncommunicative intubated patient.

[34] Schmidt M, Kindler F, Gottfried SB, et al. Dyspnea and surface inspiratory electromyograms in mechanically ventilated patients. Intensive Care Med. 2013;39:13681376.

[35] Raux M, Straus C, Redolfi S, et al. Electroencephalographic evidence for pre-motor cortex activation during inspiratory loading in humans. J Physiol. 2007;578:569-578.

[36] Raux M, Ray P, Prella M, et al. Cerebral cortex activation during experimentally induced ventilator fighting in normal humans receiving noninvasive mechanical ventilation. Anesthesiology. 2007;107:746-755.

[37] Manning HL, Schwartzstein RM. Pathophysiology of dyspnea. N Engl J Med. 1995; 333:1547-1553.

[38] O’Donnell DE, Banzett RB, Carrieri-Kohlman V, et al. Pathophysiology of dyspnea in chronic obstructive pulmonary disease: a roundtable. Proc Am Thorac Soc. 2007;4:145-168. 
[39] Lansing RW, Im BS, Thwing JI, et al. The perception of respiratory work and effort can be independent of the perception of air hunger. Am J Respir Crit Care Med. 2000;162:16901696.

[40] Banzett RB, Lansing RW, Reid MB, et al. 'Air hunger' arising from increased PCO2 in mechanically ventilated quadriplegics. Respir Physiol. 1989;76:53-67.

[41] Banzett RB, Pedersen SH, Schwartzstein RM, et al. The affective dimension of laboratory dyspnea: air hunger is more unpleasant than work/effort. Am J Respir Crit Care Med. 2008;177:1384-1390.

[42] Lansing RW, Gracely RH, Banzett RB. The multiple dimensions of dyspnea: review and hypotheses. Respir Physiol Neurobiol. 2009;167(1):53-60.

[43] Cuthbertson BH, Hull A, Strachan M, et al. Post-traumatic stress disorder after critical illness requiring general intensive care. Intensive Care Med. 2004;30:450-455.

[44] Lush MT, Janson-Bjerklie S, Carrieri VK, et al. Dyspnea in the ventilator-assisted patient. Heart Lung. 1988;17:528-535

[45] Bouley GH, Froman R, Shah H. The experience of dyspnea during weaning. Heart Lung. 1992;21:471-476.

[46] Knebel AR, Janson-Bjerklie SL, Malley JD, et al. Comparison of breathing comfort during weaning with two ventilatory modes. Am J Respir Crit Care Med. 1994;149:14-18.

[47] Powers J, Bennett SJ. Measurement of dyspnea in patients treated with mechanical ventilation. Am J Crit Care. 1999;8:254-261.

[48] Connelly B, Gunzerath L, Knebel A. A pilot study exploring mood state and dyspnea in mechanically ventilated patients. Heart Lung. 2000;29:173-179.

[49] Karampela I, Hansen-Flachen J, Smith S, et al. A dyspnea evaluation protocol for respiratory therapists: a feasibility study. Respir Care. 2002; 47:1158-1161.

[50] Twibell R, Siela D, Mahmoodi M. Subjective perceptions and physiological variables during weaning from mechanical ventilation. Am J Crit Care. 2003; 12:101-112

[51] Campbell ML, Yarandi HN, Mendez M. A Two-Group Trial of a Terminal Ventilator Withdrawal Algorithm: Pilot Testing. J Palliat Med. 2015;18:781-785

[52] Laribi S, Keijzers G, van Meer O, et al. Epidemiology of patients presenting with dyspnea to emergency departments in Europe and the Asia-Pacific region. Eur J Emerg Med. 2018 Aug 30. [Epub ahead of print]

[53] Sharp JT, Drutz WS, Moisan T, et al. Postural relief of dyspnea in severe chronic obstructive lung disease. Am Rev Respir Dis. 1980; 122:201-211. 
[54] Wysocki M, Richard JC, Meshaka P. Noninvasive proportional assist ventilation compared with noninvasive pressure support ventilation in hypercapnic acute respiratory failure. Crit Care Med. 2002;30:323-9.

[55] Demoule A, Clavel M, Rolland-Debord C, et al. Neurally adjusted ventilatory assist as an alternative to pressure support ventilation in adults: a French multicentre randomized trial. Intensive Care Med. 2016;42:1723-1732

[56] Serpa Neto A, Cardoso SO, Manetta JA, Pereira VG, Esposito DC, de Pasqualucci MO, Damasceno MC, Schultz MJ. Association between use of lung-protective ventilation with lower tidal volumes and clinical outcomes among patients without acute respiratory distress syndrome: a meta-analysis. JAMA. 2012; 308:1651-1659.

[57] Lellouche F, Dionne S, Simard S, Bussieres J, Dagenais F. High tidal volumes in mechanicallyventilated patients increase organ dysfunction after cardiac surgery. Anesthesiology. 2012;116:1072-1082.

[58] Lellouche F, Lipes J. Prophylactic protective ventilation: lower tidal volumes for all critically ill patients? Intensive Care Med. 2013; 39:6-15.

[59] Schönhofer B, Böhrer H, Köhler D. Blood transfusion facilitating difficult weaning from the ventilator. Anaesthesia. 1998;53:181-184.

[60] Lorenz KA, Lynn J, Dy SM, et al. Evidence for improving palliative care at the end of life: a systematic review. Ann Intern Med. 2008;148:147-159.

[61] Vargas-Bermúdez A, Cardenal F, Porta-Sales J. Opioids for the Management of Dyspnea in Cancer Patients: Evidence of the Last 15 Years--A Systematic Review. J Pain Palliat Care Pharmacother. 2015;29:341-52.

[62] Pisani L, Hill NS, Pacilli AMG, Polastri M, Nava S. Management of Dyspnea in the Terminally Ill. Chest. 2018 Oct;154(4):925-934.

[63] Morélot-Panzini C, O’Donnell CR, Lansing RW, et al. Aerosol furosemide for dyspnea: controlled delivery does not improve effectiveness. Respir Physiol Neurobiol. 2018;247(1):146-155

[64] Pickering EE, Semple SJ, Nazir MS, et al. Cannabinoid effects on ventilation and breathlessness: a pilot study of efficacy and safety. Chron Respir Dis. 2011;8:109-118.

[65] Simon ST, Higginson IJ, Booth S, et al. Benzodiazepines for the relief of breathlessness in advanced malignant and non-malignant diseases in adults. Cochrane Database Syst Rev. 2016;10.

[66] Lai WS, Chao CS, Yang WP, et al. Efficacy of guided imagery with theta music for advanced cancer patients with dyspnea: a pilot study. Biol Res Nurs. 2010;12:188-197.

[67] Galbraith S, Fagan P, Perkins P, et al. Does the use of a handheld fan improve chronic dyspnea? A randomized, controlled, crossover trial. J Pain Symptom Manage. 2010;39:831838 . 


\section{Figures}

Figure 1. Dyspnea assessment algorithm applicable at the patient's bedside in the intensive care setting

ICU, intensive care unit; RASS, Richmond agitation and sedation scale; CAM-ICU, confusion assessment method for ICU; D-VAS, dyspnea visual analogic scale; D-NRS, dyspnea numeric rating scale, D-Borg, modified dyspnea Borg scale ; MV-RDOS, mechanical ventilation - respiratory distress observation scale ; ICRDOS, intensive care - respiratory distress observation scale.

\section{Figure 2. Calculation of the Intensive Care - Respiratory Distress Observation Scale (IC-RDOS) and the Mechanical Ventilation - Respiratory Distress Observation Scale (MV-RDOS).}

The numerical calculation of both scales is performed by summing the respective scores of each item

\section{Figure 3. Neurophysiological Mechanisms of Dyspnea: imbalance between corollary discharges and sensory afferent signals.}

The dyspnea results from an imbalance between the intensity of the central respiratory command and the information given by the respiratory sensors coming from the lung, chest wall, respiratory muscles, airways and central and peripheral chemoreceptors. A copy of motor information from the motor cortex or the brainstem is projected onto the somatosensory cortex. Imbalance between corollary discharges (effort) and afferent signals is treated in the limbic system and leads to the sensation of dyspnea.

$\mathrm{BRC}$, brainstem respiratory center; $\mathrm{MN}$, motor neuron relay.

\section{Figure 4. Management of dyspnea}

VAS, dyspnea visual analogic scale; NRS, dyspnea numeric rating scale; Borg, modified dyspnea Borg scale 


\section{" Respiratory} motor efferent signals "

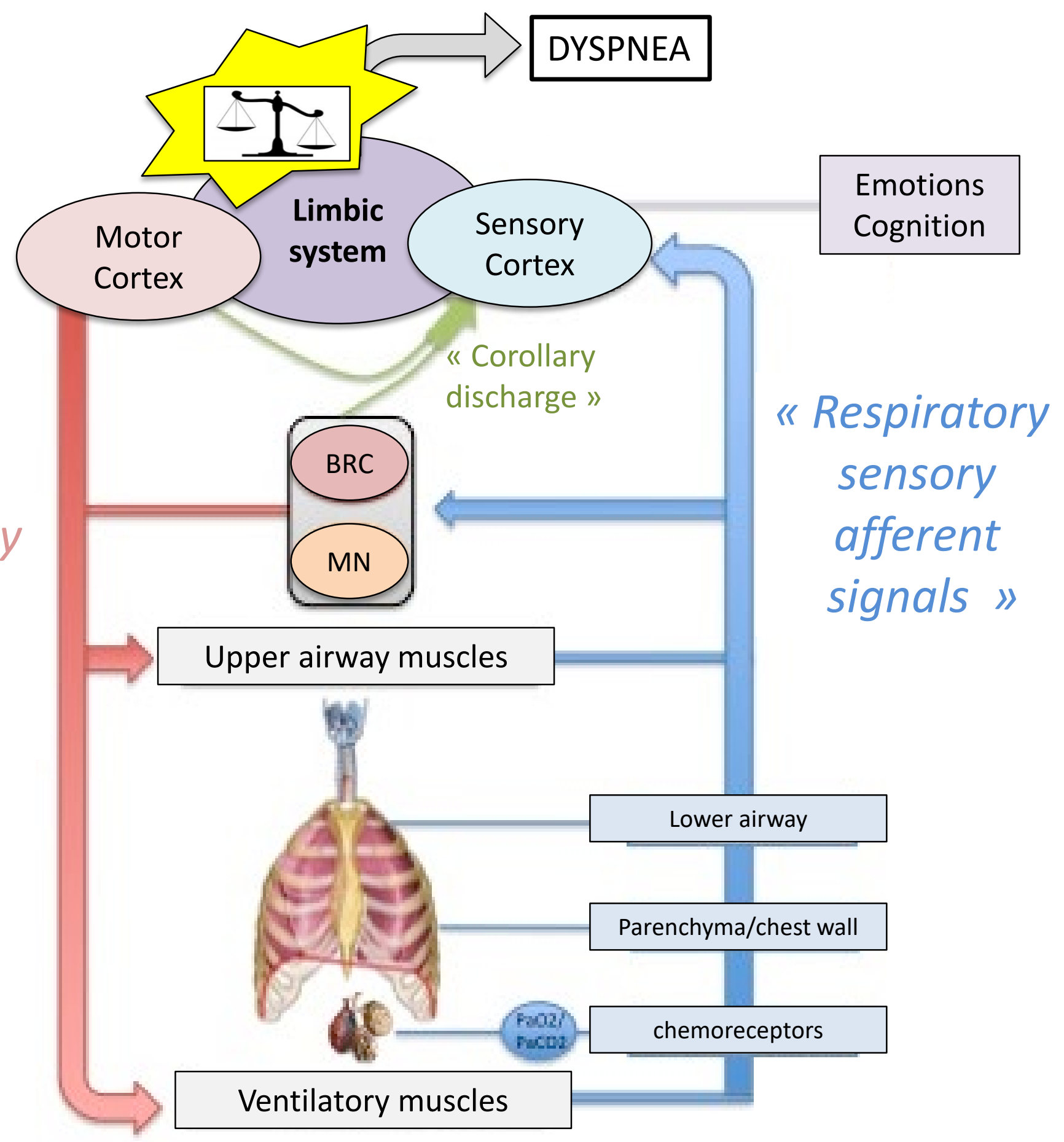




\section{A IC-RDOS calculation}

\begin{tabular}{lc}
\hline Variables & Score \\
\hline $\mathbf{0 -}$ & $\mathbf{3 , 3}$ \\
1- Heart Rate (beats/min) & $+($ Heart rate)/65 \\
2- Use of neck muscles during inspiration & \\
$\quad$ if present & $+\mathbf{1}$ \\
$\quad$ if absent & $-\mathbf{1}$ \\
3- Abdominal paradox during inspiration & $+\mathbf{1}$ \\
$\quad$ if present & $-\mathbf{1}$ \\
$\quad$ if absent & \\
$\begin{array}{l}\text { 4- Facial expression of fear } \\
\text { if present } \\
\text { if absent }\end{array}$ & $+\mathbf{1}$ \\
5- Oxygen supplemental \\
if present \\
if absent
\end{tabular}

\section{B MV-RDOS calculation}

\begin{tabular}{lc}
\hline Variables & Score \\
\hline $0-$ & 3,3 \\
1 - Heart Rate (beats/min) & $+($ Heart rate $) / 65$
\end{tabular}

2- Use of neck muscles during inspiration

$$
\begin{array}{ll}
\text { if present } & +1 \\
\text { if absent } & -1
\end{array}
$$

3- Abdominal paradox during inspiration

$\begin{array}{lc}\text { if present } & +1 \\ \text { if absent } & -1\end{array}$

4- Facial expression of fear

$\begin{array}{lc}\text { if present } & +1 \\ \text { if absent } & -1\end{array}$

5- Respiratory rate (cycles/min) $\quad+($ Respiratory rate $) / 50$ 


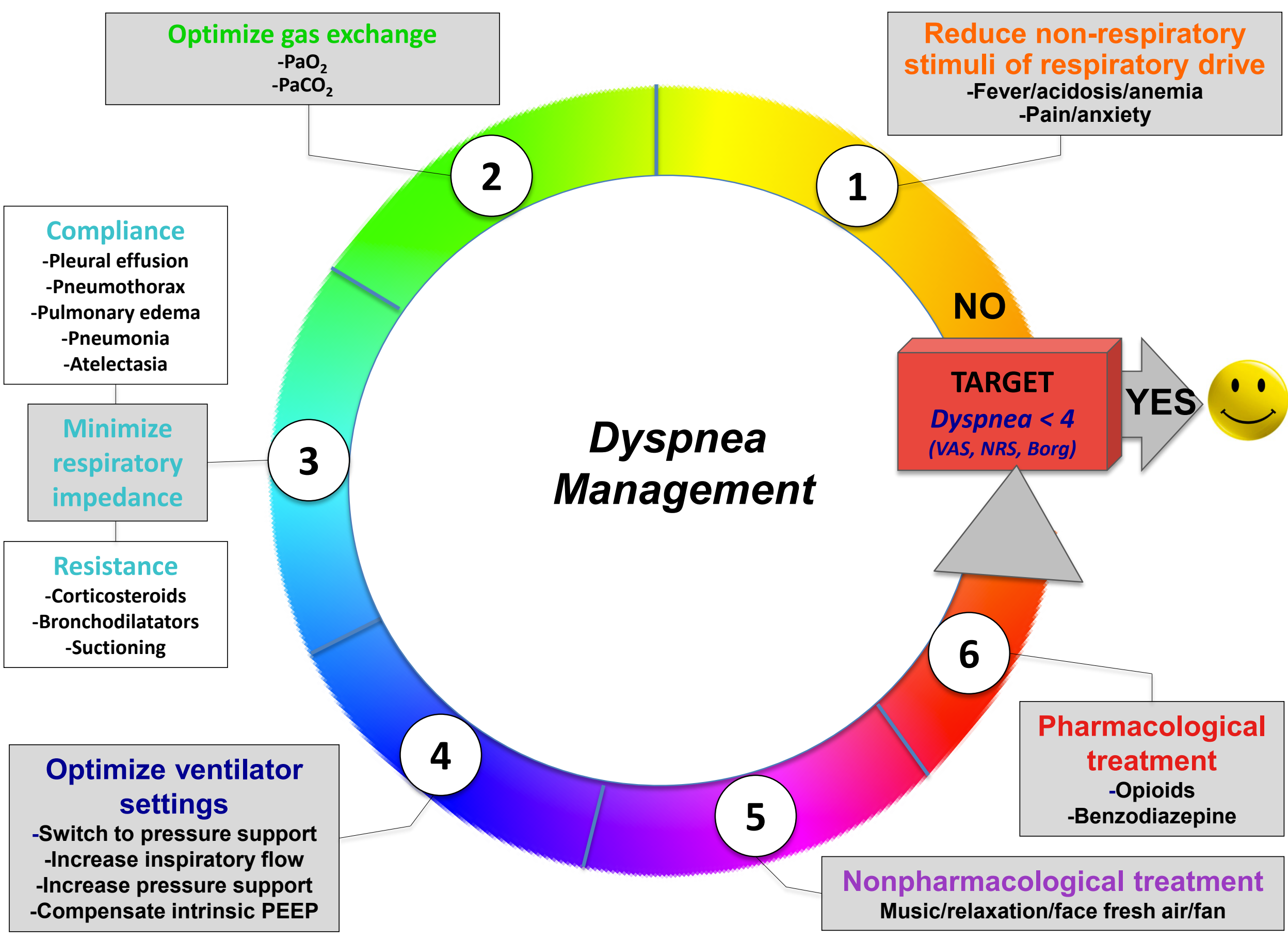

